\title{
Regularities of stress state of unsupported working occurring in a layered massif
}

\author{
Oleksii Tiutkin ${ }^{1, *}$, Nataliia Petrosian ${ }^{1}$, Anatolii Radkevych ${ }^{1}$, and Ahmad Alkhdour ${ }^{2}$ \\ ${ }^{1}$ Dnipro National University of Railway Transport named after Academician V. Lazaryan, 49010, \\ Dnipro, Lazaryan Str., 2, Ukraine \\ ${ }^{2}$ Al-Balqa Applied University, Department of civil engineering, 19117, Al-Salt, Jordan
}

\begin{abstract}
The paper defines the regularities of stress state of unsupported working occurring in a layered massif. The relevance of the performed research is substantiated by the importance of determining the stresses of the contour of unsupported working when the elastic modulus of the matrix and the layer is varied. Since the application of analytic methods for this case is complex, we used a numerical finite element method, implemented in the SCAD. We developed a finite-element model of the above working, where the elastic moduli of the matrix and the layer varied greatly, while its position was unchanged (the layer laying in the middle of the working). The results of the numerical analysis allowed us to build the regularities of three stress components. In order to normalize cases of elastic modulus variation, a dimensionless $\chi$-parameter is introduced which characterizes the relation between the elastic modulus of the matrix and the layer. The obtained regularities of the stress state of the $\chi$-parameter have a functional character and allow to determine the stresses on the contour of the unsupported working, depending on the relation between the elastic moduli of the matrix and the layer for all possible spectrum of these parameters.
\end{abstract}

\section{Introduction}

In geomechanics, mechanics of underground structures and wider in mechanics of rigid deformable body, the task of determining the stress state of an unsupported working or opening is well-elaborated. This is evidenced by a number of fundamental works that consider workings of various forms in a massif of different properties - isotropic, transversally isotropic, anisotropic, varying degrees of fracturing, elastic, elastic-plastic, viscoelastic, viscoplastic etc. [1-3]. To solve the problem of determining the unsupported working stress state, the mostly used methods, before widespread introduction of PC, were mathematical methods, for example, that of complex potentials developed by H.V. Kolosov - N.I. Muskhelishvili [1]. After the powerful development of numerical methods and their implementation on a PC in a number of calculation complexes, the solution of this problem was determined during mathematical modeling by, for example, the finite element method [4-6].

\footnotetext{
${ }^{*}$ Corresponding author: alexeytutkin@gmail.com
} 
It should be noted that at each of the two stages of the approach to this problem, with a significant spectrum of problems that have been solved, the determination of the stress state of the unsupported working in a layered massif did not receive significant development. There are objective reasons for this, namely, the complexity of obtaining closed solutions for multidirectional domains when applying the H.V. Kolosov - N.I. Muskhelishvili complex potentials method. Moreover, the special complexity was typical to the tasks in which the deformation characteristics of the surrounding massif (hereinafter - the matrix) and the layer varied jumping and had a significant difference in the elastic modulus (by times, dozens of times) [3, 7, 8]. The application of analytical methods and obtaining on their basis a stressed state of unsupported working in a layered massif was almost impossible for cases of changing the position of a layer in a matrix, its non-horizontal occurrence, variation in its thickness.

But with the advent of numerical methods and their development in software complexes the task did not get a specific solution. This is due to the fact, which has been criticized by many reputable authors of numerical methods, that the solutions obtained with their help are specific solutions that cannot be extrapolated to other specific cases. However, fully agreeing with the above criticism, but also understanding the considerable potential of numerical methods, we can propose a complex solution to the problem of determining the stress state of unsupported working in a layered massif [9]. This solution synthesizes the analyticity of mathematical methods, that is, the obtaining of strict regularities of the stress state, and the possibility of solving a large array of specific problems characterizing numerical methods.

Thus, the purpose of the given research is to determine the regularities of stress state of unsupported working occurring in a layered massif; herewith they are obtained based on the finite element method at variation of the deformation properties, namely, the elastic moduli of the matrix and the layer. The obtained regularities prove that it is the relation of elastic moduli, and not their specific value, which is responsible for the formation of stresses on the contour of unsupported working.

\section{Methods}

Almost all classical and fundamental textbooks or manuals on rocks mechanics, mechanics of underground structures and geomechanics, when determining the massif thickness, emphasize the complexity of its research. It is also noted that rock massifs, depending on the difference in the deformation characteristics of the layers, are divided into two types: 1) those composed of layers without sharp jumps of deformation properties; 2) those with a deformation property change by jump [3]. However, no specific boundary was not given that separates the first type from the second one, which could be expressed in relation to the elastic moduli of the layers.

The work [3] presents a generalized mathematical notion of the solidity of a rock massif, in particular the layered one, proposed by H.A. Krupennykov. This notion of "quasi-solid massif" is written in mathematical form as follows:

$$
\Delta A<\varepsilon \text { at } \Delta a<l_{0},
$$

where $\Delta A$ - difference in the values of stresses in the adjacent points of the massif with coordinate increment $\Delta a ; l_{0}$ - linear dimension of volume element; $\varepsilon$ - allowable error in the definition of $A$ (up to $15 \%$ of the mean value).

This mathematical criterion of "quasi-solid massif" in numerical calculations of rock masses does not play the role of boundary, since in the intact layered massif the first part of the criterion is always performed automatically (error of the stresses is less than $15 \%$ of the 
mean value), and in case of the working the massif automatically ceases to be "quasi-solid" and its condition is characterized by significant concentration of stresses.

Therefore, another criterion should be taken, which would help to determine the case of a layered massif, and would have specific numerical values. As such a criterion, we introduce $\chi$-parameter, which characterizes the relation between the elastic moduli of the matrix and the layer:

$$
\chi=\frac{E_{m}}{E_{s}},
$$

where $E_{m}$ - elastic modulus of the matrix; $E_{s}$ - elastic modulus of the layer.

A finite-element model of unsupported working in Structure CAD (license number F755B84 (KMBKB RA 4810)) [10] occurring in a layered massif was developed and it was calculated for ten values of the $\chi$-parameter (Fig. 1).

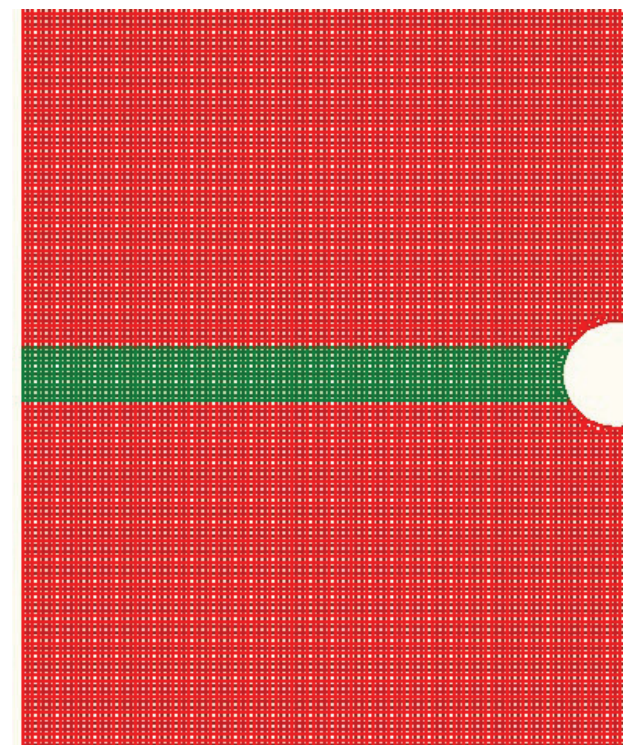

Fig. 1. Finite-element model of unsupported working occurring in a layered massif.

The finite-element model presents a $40 \times 40$ meter rock massif, which for the greater accuracy is discretized into finite elements of $0.5 \times 0.5 \mathrm{~m}$ by automatic triangulation (with the merging of triangular elements into rectangular ones). The type of the plane elasticity problem elements were used, which allows simulating the work of the surrounding layered massif. The number of nodes 97128, the number of finite elements 48112, which characterizes the problem as a middle dimension one.

The basic equation of the finite element method in the Structure CAD complex is determined on the basis of the variational method of solving the problems of the theory of elasticity. For this purpose, a continuous homogeneous isotropic elastic body of volume $V$, which is in equilibrium under the influence of volume forces $Q$ and surface forces $P$, is discretized on a finite number of elements of different shapes and sizes.

It is accepted that all forces are applied to the vertices of the elements. Unknown components of the elements vertices displacements are denoted by $u_{i}, v_{i}, w_{i}$, where $i=1,2,3 \ldots n ; n$ - number of vertices of elements. The displacement function has the form of Rayleigh-Ritz sum, which is often used to solve a problem in a variational way: 


$$
\left.\begin{array}{l}
u=\sum_{i=1}^{n} u_{i} f_{i}(x, y, z) ; \\
v=\sum_{i=1}^{n} v_{i} \varphi_{i}(x, y, z) ; \\
w=\sum_{i=1}^{n} w_{i} \psi_{i}(x, y, z),
\end{array}\right\}
$$

where $f_{i}, \varphi_{i}, \psi_{i}$ are known coordinate functions satisfying the boundary conditions.

The potential energy of the system is determined by the equation:

$$
U=U(u, v, w)-U(Q, P) \text {. }
$$

Then the potential of external forces is expressed by the equation:

$$
U(Q, P)=\iiint_{V}\left(Q_{x} u+Q_{y} v+Q_{z} w\right) d V-\iint_{\Omega}\left(P_{x} u+P_{y} v+P_{z} w\right) d \Omega,
$$

where $Q_{x}, Q_{y}, Q_{z}, P_{x}, P_{y}, P_{z}$ - axis projection on the $x, y, z$ of volume $V$ and surface $\Omega$ forces respectively.

Assigning the deformation characteristics and boundary conditions on the $x, y, z$, as well as applying the gravity action to the model, are the final steps before conducting numerical calculations.

\section{Results and discussion}

After the model was created, its full calculation with the matrix expansion by the multifrontal method was performed. Figure 2 shows the characteristic isolines and isofields of the analyzed stresses in the contour of unsupported working occurring in a layered massif.

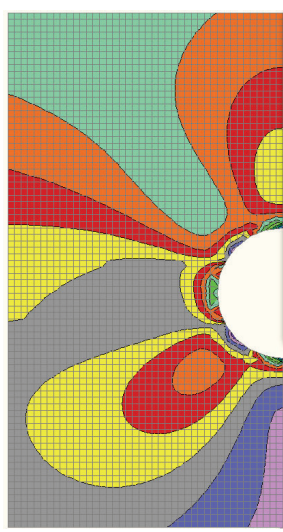

1)

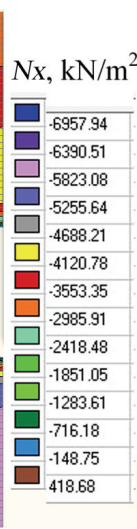

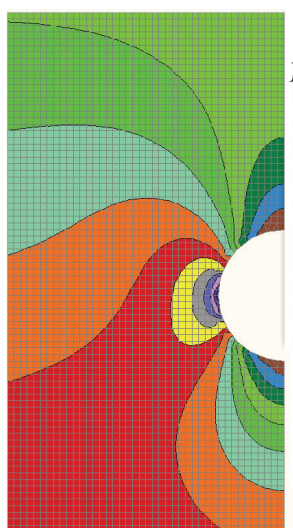

2)
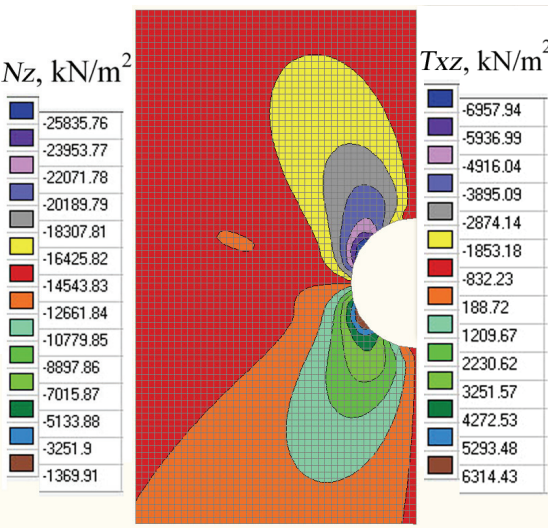

3)

Fig. 2. Characteristic isolines and isofields of stresses of the contour of unsupported working occurring in a layered massif ( $E_{m}=30 \mathrm{MPa}, E_{s}=15 \mathrm{MPa}$ ): 1) $N_{x}$ - normal stresses on the horizontal axis; 2) $N_{z}$ - normal stresses on the vertical axis; 3) $T_{x z}$ - tangential stresses in the vertical plane.

The array of results in the course of numerical analysis was analyzed, and for the further determination of the laws of the stressed state there were chosen five characteristic points of the working contour, in which the values of the stress components were determined (Fig. 3). 


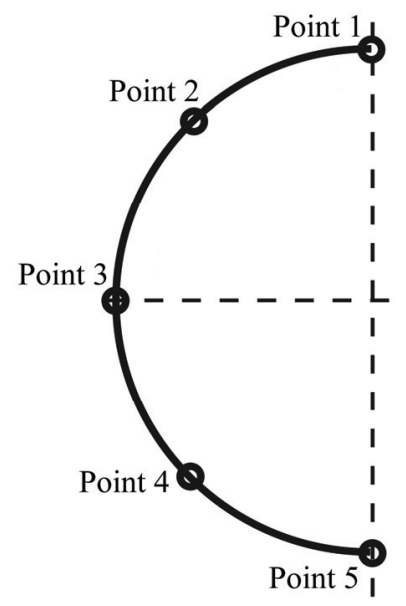

Fig. 3. Scheme of characteristic points on the contour of unsupported working.

The obtained results for characteristic points allowed to construct the graphs of dependency of stresses of the unsupported working occurring in a layered massif on the $\chi$ parameter (Fig. 4-6).

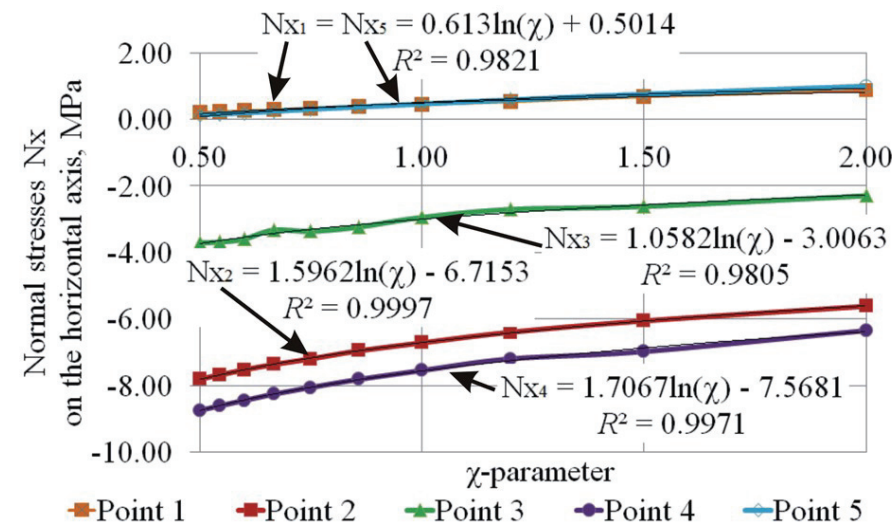

Fig. 4. Graphs of dependency of $N_{x}$ stresses on the contour of unsupported working on $\chi$-parameter.

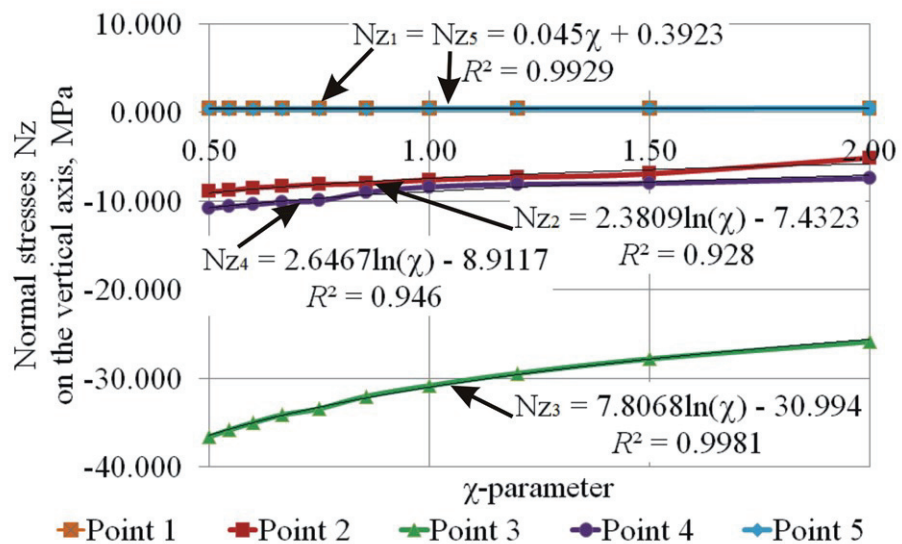

Fig. 5. Graphs of dependency of $N_{z}$ stresses on the contour of unsupported working on $\chi$-parameter. 


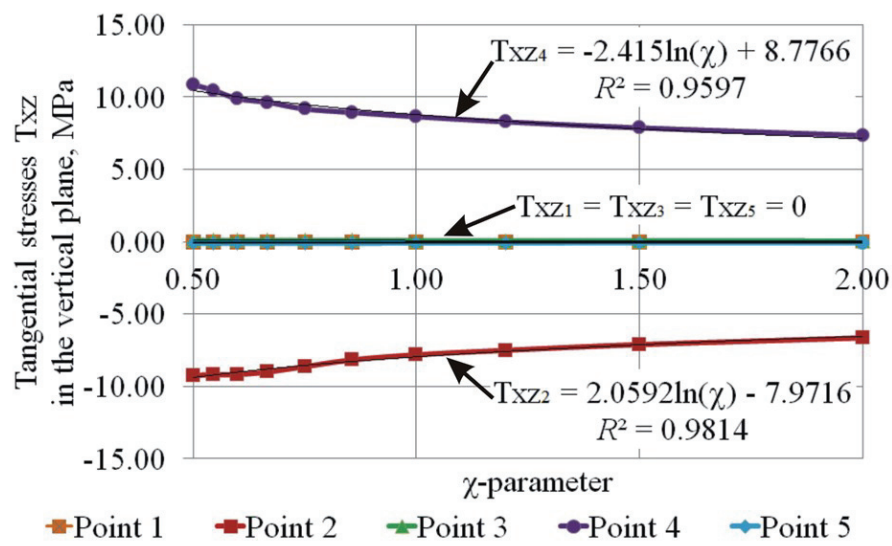

Fig. 6. Graphs of dependency of $T_{x z}$ stresses on the contour of unsupported working on $\chi$-parameter.

The graphs are approximated, and the obtained logarithmic patterns of approximation have a correlation coefficient $R^{2}=0.97 \ldots 0.99$, which indicates their almost functional character. That is, with the help of the found regularities it is possible to determine the stress state in the five characteristic points of the contour of unsupported working occurring in a layered massif.

To confirm the author's constructions, which are substantiated by the logarithmic regularities of dependency of the stress state in the characteristic points of the working contour on the $\chi$-parameter, a control calculation was performed with the value $\chi=2$, but with changed deformation characteristics of the matrix and the layer (Fig. 7).

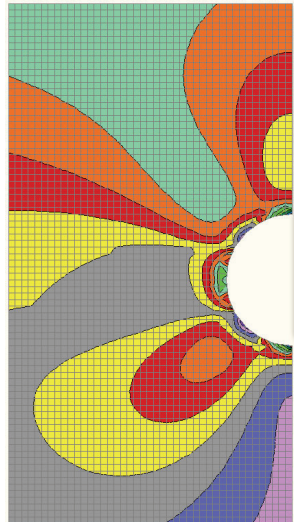

1)

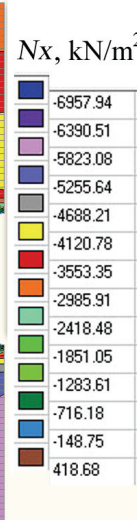

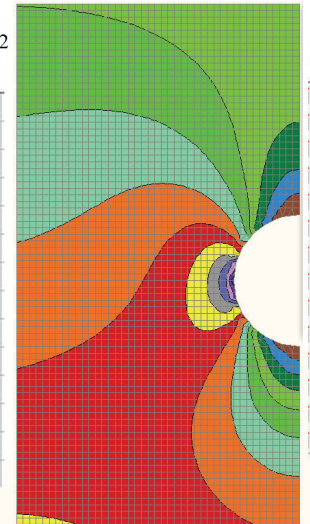

2)

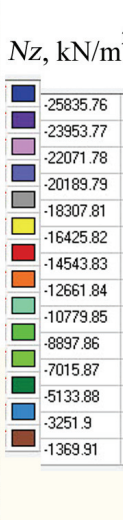

3

Fig. 7. Characteristic isolines and isofields of stresses of the contour of unsupported working occurring in a layered massif ( $E_{m}=6000 \mathrm{MPa}, E_{s}=3000 \mathrm{MPa}$ ): 1) $N_{x}$ - normal stresses on the horizontal axis; 2) $N_{z}$ - normal stresses on the vertical axis; 3) $T_{x z}$ - tangential stresses in the vertical plane.

Comparison of stress components presented in Figure 2 and 5 shows their identity, as well as makes it possible to conclude that the entire spectrum of cases of unsupported working in a layered massif at different deformation properties of the matrix and the layer is homologous with the same $\chi$-parameter. That is, no matter how the values of the elastic moduli of the matrix and the layer are changed, with the same values of the $\chi$-parameter, the stress state of the cases will be identical. 


\section{Conclusions}

The obtained regularities of the stresses of unsupported working occurring in a layered massif are functional in nature and logarithmic (only for two points they are linear in nature). This allows in practical calculations at different values of $\chi$-parameter without conducting additional actions, to calculate the stresses in the five characteristic points of the working, only by determining the relation between the deformation properties of the matrix and the layer.

The determined regularities for the case of a layer passing through the middle of the working and their development allow us to predict that for other cases (the layer on top or bottom of the working) such regularities can be found as well. This determines the further ways of solving the problem, which can be expanded by examining the variation and other parameters (geometrical parameters of the working, the layer, its position, etc.). The further obtained results will allow, on the basis of the numerical finite element method, to find analytical dependences of the stress state of the unsupported working occurring in a layered massif for various variants of the properties of the working, the matrix and the layer.

\section{References}

1. Savin, G.N. (1968). Raspredeleniye napryazheniy okolo otverstiy. Kyiv: Naukova dumka

2. Sazhin, V.S. (1968). Uprugo-plasticheskoye raspredeleniye napryazheniy vokrug gornykh vyrabotok razlichnogo ochertaniya. Moskva: Nauka

3. Baklashov, I.V., Kartoziya, B.A. (1984). Mekhanika podzemnykh sooruzheniy $i$ konstruktsii krepey. Moskva: Nedra

4. S.K. Dhir J. Appl. Mech., 48, 4 (1981)

5. Mostkov, V.M. (1986). Podzemnyye gidrotekhnicheskiye sooruzheniya. Moskva: Vysshaya shkola

6. N.T. Younis Mech. Res. Commun., 33, 3 (2006)

7. Frolov, Yu.S., Golitsynskiy, D.M., Ledyayev, A.P. (2001). Metropoliteny. Moskva: Zheldorizdat

8. S. Monti Commun. Sci. Lett. Univ. Žilina 20, 3 (2018)

9. Tiutkin, O.L., Petrenko, V.D., Huzchenko, V.T., Tiutkin, D.V. (2014). Analysis of deformed state structures of the Kyiv metro running tunnels on a transition zone from spondylov's clay to buchatskiy sands, Science and Transport Progress. Bulletin of Dnipropetrovsk National University of Railway Transport, 4 (52), 127-138.

10. Petrosyan, N.K., Tyutkin, A.L. (2017). Ekspress-analiz napryazhennodeformirovannogo sostoyaniya nezakreplennoy vyrabotki na osnove modeli $\mathrm{s}$ edinichnymi parametrami, Mosty ta tuneli: teoriia, doslidzhennia, praktyka, 11, 60-66 